\title{
Two Classes of Highly Similar Coiled Coil-Nucleotide Binding-Leucine Rich Repeat Genes Isolated from the Rps1-k Locus Encode Phytophthora Resistance in Soybean
}

\author{
Hongyu Gao, Narayanan N. Narayanan, Lori Ellison, and Madan K. Bhattacharyya \\ Department of Agronomy, lowa State University, Ames, lowa 50011, U.S.A.
}

Submitted 31 March 2005. Accepted 2 June 2005.

\begin{abstract}
A series of single genes protect soybean from the root and stem disease caused by the oomycete pathogen Phytophthora sojae. In the last two decades, Rps1-k has been the most stable and widely used Phytophthora resistance gene for the major soybean-producing regions of the United States. Four highly similar genes encoding coiled coil-nucleotide binding-leucine rich repeat (CC-NB-LRR)-type proteins were isolated from the Rps 1 -k locus. These genes were grouped into two classes based on their sequence identity. Class I contains three genes with identical open reading frames $(\mathrm{ORF})$ and $5^{\prime}$ end regions. Two of these genes were also identical at the $3^{\prime}$ untranslated regions; the third gene showed a recombination breakpoint in the $3^{\prime}$ untranslated region resulting in the combination of $3^{\prime}$ end sequences of members from both classes. Reverse transcription-polymerase chain reaction analyses suggested that members of both classes of genes are transcribed at low levels. Representative members from each gene class were expressed in transgenic soybean plants. Analyses of independent $R_{0}, R_{1}, R_{2}$, and $R_{3}$ progeny populations suggested that both gene classes confer Phytophthora resistance in soybean. A possible evolutionary mechanism for the Class I gene family is proposed.
\end{abstract}

Constantly under attack by various pathogens, plants have evolved a network of preformed and inducible responses against pathogen invasion (Hammond-Kosack and Jones 1996). Active defense responses are induced following the recognition of pathogenic isolates by host resistance $(R)$ genes. Proteins encoded by $R$ genes are thought to recognize pathogen proteins encoded by avirulence (Avr) genes. The recognition between matching pairs of host and pathogen genes was first described by Flor (1955) in the flax and Melampsora lini interaction. Over $40 R$ genes have been cloned and characterized, and based on their predicted protein structures, cloned $R$ genes can be broadly classified into several large groups (Hulbert et al. 2001; Martin et al. 2003). The majority of R proteins contain nucleotide binding (NB) and leucine-rich repeat (LRR)

Corresponding author: M. K. Bhattacharyya;

E-mail: mbhattac@iastate.edu

Nucleotide sequence data are available in the GenBank database under accession numbers AY963292 and Y963293.

* The $e$-Xtra logo stands for "electronic extra" and indicates the HTML abstract available on-line contains supplemental material not included in the print edition. domains. The NB-LRR group can be further divided into three classes: i) Class I genes carry an N-terminal coiled-coil or leucine zipper domain, ii) Class II genes contain a toll interleukin 1 receptor domain showing homology to a domain found in Drosophila toll and mammalian interleukin-1 receptors, and iii) Class III includes NB-LRR genes with unusual functional motifs such as RRS1-R and LR21 (Deslandes et al. 2002; Huang et al. 2003; Pan et al. 2000; Whitham et al. 1994).

Cloning and characterization of a large number of $R$ genes have shown no association between $R$ gene structures and types of encoded resistance. For example, CC-NB-LRR-type $R$ genes from various plant species confer resistance against viruses, bacteria, fungi, oomycetes, nematodes, and aphids (Ballvora et al. 2002; Bent et al. 1994; Ori et al. 1997; Vos et al. 1998; Whitham et al. 1994). The cloning of $R$ genes and their corresponding $A v r$ genes led to the demonstration of direct interactions between $\mathrm{R}$ and Avr proteins for a limited number of plant-pathogen interactions (Lahaye 2004). Recent data, however, showed that R proteins can guard complexes of proteins consisting of one or more host factors, so-called virulence targets, and pathogen avirulence factors in order to prevent disease development. In the absence of the guard, the plant is susceptible. Presumably $\mathrm{R}$ proteins monitor the common host factors for initiation of active defense responses (Marathe and Dinesh-Kumar 2003). Multiple mechanisms may determine the outcome of plant-pathogen interactions. For example, Shao and associates (2003) demonstrated that RPS5-mediated resistance is specifically activated upon cleavage of the host protein PBS1 by the corresponding avirulent protein avrPphB.

Soybean is a major oil seed crop. In North America, soybean often suffers from root and stem rot disease caused by the oomycete pathogen, Phytophthora sojae; the annual crop losses from this disease are estimated to be about $\$ 273$ million (Wrather et al. 2001). Resistance encoded by Rps (resistance to $P$. sojae) genes has been providing significant protection against this disease for the last four decades. Among $15 \mathrm{Rps}$ genes, Rps 1 -k has been conferring resistance against a large number of the $P$. sojae races and, therefore, has been widely used in soybean cultivars grown in the midwestern United States (Sandhu et al. 2004; Schmitthenner et al. 1994). Despite the economic importance of disease resistance in soybean, the progress toward cloning $R$ genes has been very slow. This is primarily because of the complexity of the soybean genome for positional cloning experiments and difficulties associated with transformation procedures for gene identification.

Single dominant avirulence genes corresponding to 11 of the Rps genes have been mapped. Several P. sojae Avr genes have 
been targeted for positional cloning, and recently, Avrlb has been cloned (Shan et al. 2004; Tyler 2002). Two genes, Avrlb1 and $A v r l b-2$, are required for expression of the Avrlbencoded avirulence function. Both genes are physically linked and were cloned from the $A v r l b$ locus. $A v r l b-2$ regulates the accumulation of the $A v r l b-1$ transcripts. Avr $1 b-1$ encodes a secreted protein that elicits a resistance response in soybean cultivars carrying Rpsl-b (Shan et al. 2004).

Candidate genes for $R s v 1, R p s 2$, and Rps4 have recently been reported (Graham et al. 2002; Hayes et al. 2004; Sandhu et al. 2004). Only Rpgl-b, conferring bacterial resistance, has recently been isolated (Ashfield et al. 2004). No other $R$ genes from any legume species have been cloned. We have isolated a large family of coiled coil-nucleotide binding-leucine rich repeat (CC-NB-LRR)-type genes from the Rps $1-\mathrm{k}$ region (Bhattacharyya et al. 2005). Here, we report that four members of the gene family are located at the Rps $1-\mathrm{k}$ locus. These four genes are grouped into two classes, one of which contains three identical genes. A member from each class has been shown to confer resistance in transgenic soybean plants. A possible mechanism for the evolution of highly similar functional Rps genes is discussed.

\section{RESULTS}

\section{Identification and characterization}

of highly similar candidate genes from the Rps 1-k region.

We have isolated a contiguous, approximately 145-kb DNA fragment from the Rpsl-k locus (Bhattacharyya et al. 2005). Three overlapping bacterial artificial chromosome (BAC) clones, BAC18, BAC43, and BAC99, span this DNA fragment. All three BACs were sequenced to near completion. Except for a predicted pseudo serine/threonine kinase and four CC-NBLRR-type disease resistance genes, no other disease resistance gene-like sequences were identified from these BAC clones. Therefore, we designated the four CC-NB-LRR-type genes as the candidate Rps $1-\mathrm{k}$ genes Rps $1-\mathrm{k}-1$ to $R p s 1-\mathrm{k}-4$ and grouped them into two classes (accession numbers AY963292 and AY963293). Class I consists of Rps1-k-1, Rps 1-k-3, and Rps 1k-4, whereas Class II contains Rps $1-\mathrm{k}-2$. Rps $1-\mathrm{k}-1$ and Rps 1 -k4 are identical genes but were isolated from two nonoverlap- ping BACs, BAC18 and BAC99. Therefore, they are considered as two independent genes. At the $5^{\prime}$ untranslated region and the open reading frame (ORF), Rps $1-\mathrm{k}-1, R p s 1-\mathrm{k}-3$, and Rps l-k-4 are identical. However, the $3^{\prime}$ untranslated region of Rps $1-\mathrm{k}-3$ evolved from a recombination event between $3^{\prime}$ end sequences of Class I and II genes (Fig. 1). The recombination breakpoint in Rpsl-k-3 was confirmed through molecular analyses of binary clones, BAC clones, and soybean genomic DNA (data not shown). The nucleic acid and deduced amino acid sequence identities between ORFs of Class I and II genes were 93 and $89.9 \%$, respectively. Six structural domains were identified among the deduced candidate Rps1-k proteins (Fig. 2). The N-terminal region (domain A) did not show similarity to any known motifs or domains. Domain B contained the CC motif. The putative NB-ARC (nucleotide-binding adaptor conserved in Apaf-1, apoptosis protease activating factor-1, $\mathrm{R}$ gene products, and CED-4) domain was identified in domain $\mathrm{C}$ (van der Biezen and Jones 1998). A short spacer sequence (domain D) was observed between the NB-ARC domain and the LRR region (domain E). In Rpsl-k-2 (Class II), the C-terminal LRR region contains 27 imperfect LRR, one of which is absent in Class I Rps1-k proteins (Fig. 2). The C-terminus (domain F) did not show identity to any known motifs or domains.

\section{Candidate Rps1-k genes are transcribed at low levels.}

In order to determine the gene structure of the candidate genes and establish that they are transcribed genes, we screened an unamplified cDNA library carrying approximately $4.6 \times 10^{6}$ PFU. Seven cDNAs representing four classes of genes were isolated (Bhattacharyya et al. 2005). Sequence alignments between cDNAs and candidate gene sequences revealed two introns located in the $3^{\prime}$ untranslated region (Fig. 1). However, none of these cDNAs showed $100 \%$ identity to any of the candidate Rps $1-\mathrm{k}$ genes (data not shown).

A two-step reverse transcription-polymerase chain reaction (RT-PCR) approach was utilized to identify transcripts of the candidate Rpsl-k gene family. Total RNAs isolated from leaves of cultivar Williams 82 were reverse transcribed and then PCR-amplified using candidate Rps 1-k-1- and Rps 1-k-2specific primers (Fig. 3A). The first PCR was performed using Rps1-k-1- and Rps1-k-2-specific forward primers and a com-

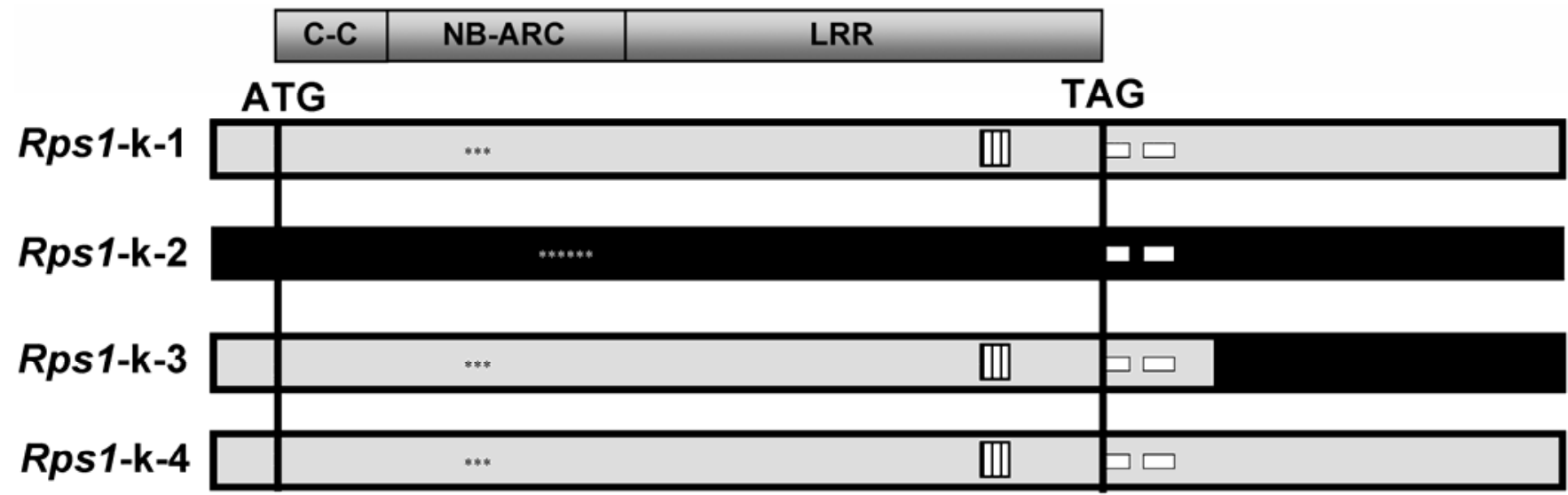

$1 \mathrm{~kb}$

Fig. 1. The Rps1-k gene family is comprised of two classes of highly similar genes. Class I contains Rps1-k-1, Rps1-k-3, and Rps 1-k-4. Rps1-k-1 and Rps1$\mathrm{k}-4$, showing $100 \%$ identity (gray color), were isolated from two nonoverlapping bacterial artificial chromosome clones. Rps 1 -k-3 contains a recombination breakpoint at the 3' untranslated region (black color for exchanged sequences from Rps1-k-2). C-C = coiled-coil domain; NB-ARC = nucleotide-binding adaptor conserved in Apaf-1, apoptosis protease activating factor-1, R gene products, and CED-4 (van der Biezen and Jones 1998) domain; LRR = leucine rich repeat domain; * indicates single deletion; the square with vertical lines represents a 63 -nt deletion; the white rectangles depict introns. 
mon reverse primer. The targeted regions included two introns, and therefore, PCR products from contaminating genomic DNA were 344 bp larger than the RT-PCR products (Fig. 3B). The second PCR was conducted using the diluted gel-purified Rps1-k-1- or Rps1-k-2-specific RT-PCR products as templates. Rps1-k-1- or Rps1-k-2-specific primer pairs were used in the second PCR step (Fig. 3C). PCR products of the second PCR step were directly sequenced and compared with the Rps $1-\mathrm{k}-1$ and Rps 1-k-2 gene sequences. Complete identities were observed between RT-PCR products and the corresponding Rps 1$\mathrm{k}$ gene sequences (data not shown). We amplified 573 and 648 bp of the LRR domains of Rps $1-\mathrm{k}-1$ and Rps $1-\mathrm{k}-2$, respectively. These RT-PCR products contained five to six copies of the consensus $x x \operatorname{LxLxx}$ ( $\mathrm{x}$ can be any amino acid residues) repeat sequence of the LRR region. The amplified regions between the two classes of genes were distinguished by the presence of a 63-nt deletion in the Class I Rps I-k genes. The solvent-exposed residues within the consensus xxLxLxx repeat sequence of the LRR domain have been shown to be highly divergent and under substantial diversifying selection (Meyers et al. 1998; Parniske et al. 1997). Therefore, it is very unlikely that RT-PCR products originated from transcripts of paralogous Rpsl-k gene sequences rather than from that of the Rpsl-k candidate genes, and we conclude that both classes of candidate $R p s 1-\mathrm{k}$ genes are transcribed at very low levels.

\section{Candidate Rps 1-k genes conferred stable race-specific Phytophthora resistance in transgenic soybean plants.}

To establish the functional identity of candidate Rps $1-\mathrm{k}$ genes, three binary plasmids, p43-JP1, p99-6A, and p43-10, carrying candidate Rps $1-\mathrm{k}-1, R p s 1-\mathrm{k}-2$, and $R p s 1-\mathrm{k}-3$ genes, respectively, were introduced into the soybean cultivar Williams 79 using Agrobacterium-mediated transformation (Paz et al. 2004). One transformant for Rps $1-\mathrm{k}-1$, six independent transformants for Rpsl-k-2, and three for Rpsl-k-3 were generated. Trifoliates of independent transformants were detached from the greenhouse-grown, basta-resistant transgenic soybean plants. Most of the $\mathrm{R}_{0}$ transformants showed Phytophthora resistance against $P$. sojae race 4 (Fig. 4A). Phenotypic analysis of the $\mathrm{R}_{1}$ generation of independent transformants demonstrated that all three genes confer resistance in soybean leaves against the $P$. sojae race 4 and isolate 997A-2-3 (Fig. 4 and Table 1). Progenies of the single transformant T-1-1 containing Rps1-k-1, two independent transformants, T-2-1 and T-2-6, carrying Rps $1-\mathrm{k}-$ 2, and three, T-3-1, T-3-2, and T-3-3, carrying Rps 1-k-3, showed a 3:1 segregation ratio for resistance and susceptibility

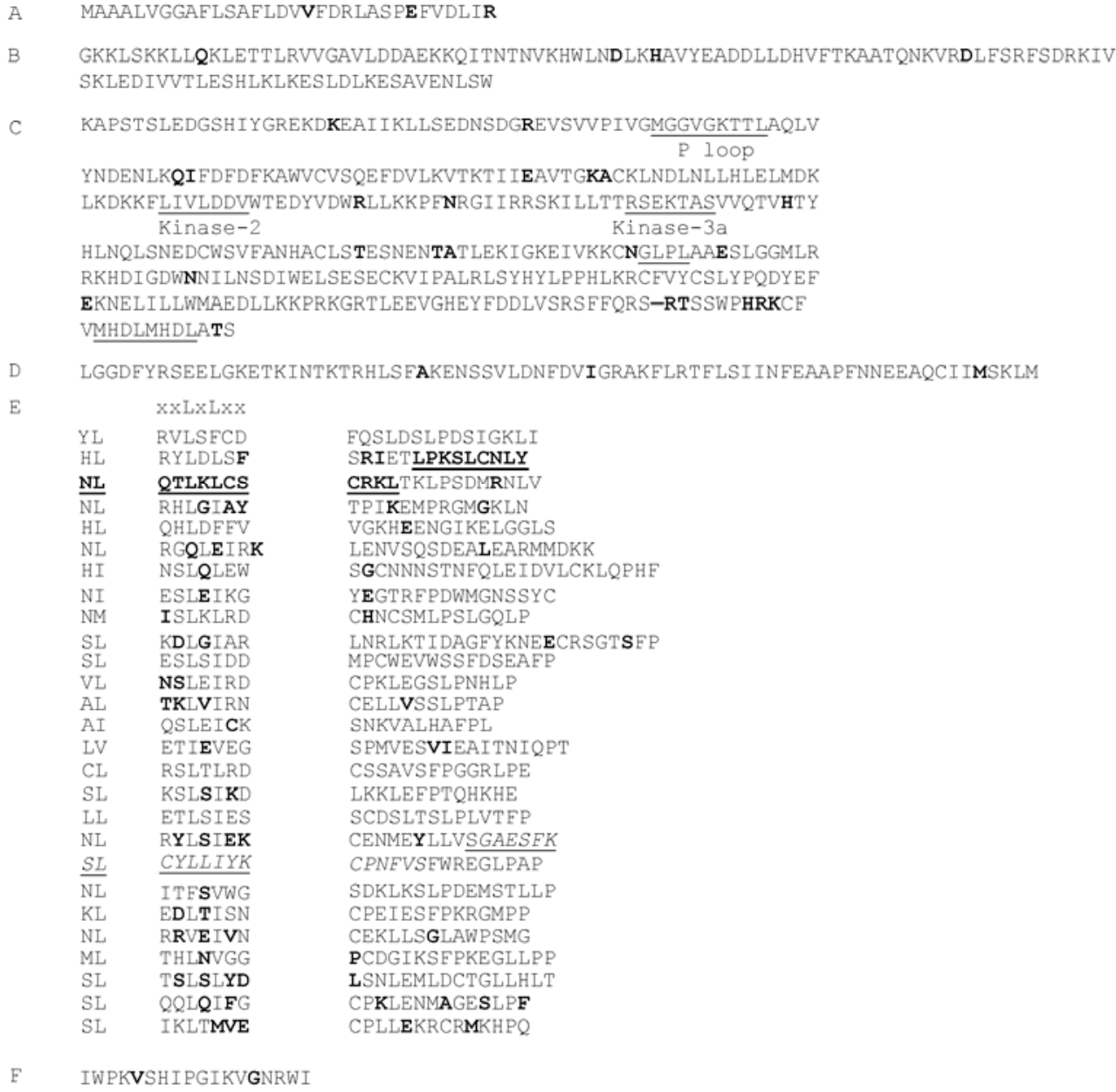

F IWPKVSHIPGIKVGNRWI

Fig. 2. Structure of the predicted Rps1-k proteins. The predicted, complete amino acid sequence of Rps 1 -k-2 is used to describe the structure (six domains A to F). The bold residues are the sites that vary between the Class I and Class II Rps1-k proteins. Domain A is the N-terminus with no homologies to known motifs or domains. Domain B is the coiled-coil domain predicted using the COILS program (Lupas, 1997). Domain C is the NB-ARC (nucleotide-binding adaptor conserved in Apaf-1, apoptosis protease activating factor-1, R gene products, and CED-4) domain. Conserved P loop, kinase-2, and kinase-3a sequences, GLPL, and MHD motifs are underlined. Domain D is the spacer that separates NB-ARC and LRR domains. Domain E is the leucine-rich repeat (LRR) domain. The consensus sequence in the LRR region is indicated by xxLxLxx just above the alignment of LRR sequences (L can be replaced by $\mathrm{V}$, $\mathrm{F}$, or M). The leucine-zipper-like motif identified in the LRR domain is underlined. One 21-amino acid LRR repeat absent in the Class I Rps1-k proteins is shown in italics and underlined. Domain F represents the C-terminus, which does not contain any known motifs or domains. The structural domains of predicted proteins were identified primarily using Pfam and by comparison with previously described $R$ genes. 
in either $R_{1}$ or $R_{2}$ generation (Table 1 ). Progenies of the bastaresistant T-2-4 transformant were all susceptible to the pathogen, presumably due to absence of transgene expression and, therefore, were considered as the negative control.

Wounded hypocotyls of $\mathrm{R}_{2}$ or $\mathrm{R}_{3}$ populations containing candidate Rps 1-k genes were inoculated with both avirulent and virulent $P$. sojae isolates, in order to determine if the resistance conferred in transgenic plants was race-specific. Race 4 , used in the leaf inoculation experiment, was found to be more aggressive on wounded Williams 82 hypocotyls of light-grown seedlings, and the cultivar containing Rps $1-\mathrm{k}$ consistently failed to produce a resistant phenotype. Race 18 and isolate 997A-2-3 were avirulent, while race 25 was virulent to Williams 82. $\mathrm{R}_{2}$ and $\mathrm{R}_{3}$ progenies containing either $R p s 1-\mathrm{k}-1$ or Rpsl-k-2 were resistant to race 18 and isolate $997 \mathrm{~A}-2-3$ but were susceptible to race 25 (Table 2). The activity of both Rps 1-k-1 and Rps1-k-2 genes was also tested in the recipient cultivar Williams that does not contain any known Rps genes (Table 2, the 7aD- and 30-85- transformants). These results suggested that both Class I and II genes encode race-specific Phytophthora resistance.

\section{Cosegregation of an Rps 1- $k$-2 transgene} with the complemented race-specific resistance.

$\mathrm{R}_{2}$ families were investigated to determine the association of integrated transgenes with the disease-resistant phenotype. $\mathrm{R}_{2}$ plants of two independent $\mathrm{R}_{0}$ plants, $\mathrm{T}-2-1$ and $\mathrm{T}-2-6$, carrying Rps 1-k-2, and $\mathrm{R}_{2}$ progenies of $\mathrm{T}-3-1$ carrying $R p s 1-\mathrm{k}-3$ were investigated for the integration of transgenes. Progenies of $10 R_{1}$ families developed from individual $\mathrm{R}_{0}$ plants were also studied. $R_{2}$ progenies segregated for resistance and susceptibility.
$\mathrm{R}_{2}$ families developed from these transformants were investigated for association between integrated transgenes and the complemented resistant phenotype. Inoculation of wounded hypocotyls of 10 light-grown $\mathrm{R}_{1: 2}$ families originating from the T-2-6 $\mathrm{R}_{0}$ transformant carrying Rps $1-\mathrm{k}-2$ showed a 1:2:1 segregation ratio for i) homozygous resistant phenotype, ii) segregating resistance and susceptible phenotypes, and iii) homozygous susceptible phenotype. Southern analysis showed that multiple copies of the transgene were integrated into the soybean genome. Progenies of randomly selected $R_{2}$ plants showed that the complemented resistant phenotype was associated with the integration of a single Rps $1-\mathrm{k}-2$ transgene copy.

Rps 1-k-specific resistance has been shown to be expressed in etiolated hypocotyls (Ward et al. 1979). Therefore, we investigated dark-grown seedlings for expression of Rps l-k-2 transgene-mediated resistance. Symptoms were recorded $24 \mathrm{~h}$ following inoculation of intact hypocotyls with $P$. sojae zoospores. DNA blot analysis of selected resistant and susceptible seedlings again showed complete association between the expression of resistant phenotype and integration of a specific Rps 1k-2 transgene copy (Fig. 5, arrow). Although many copies of Rps $1-\mathrm{k}-2$ transgenes were segregating, only a single Rps $1-\mathrm{k}-2$ transgene copy was shown to associate with the expression of Phytophthora resistance in both light- and dark-grown seedlings. Presumably, other integrated transgene copies failed to confer any Phytophthora resistance. Among $\mathrm{R}_{2}$ progenies of $\mathrm{T}$ $2-5$, no association between transgene copies and complemented resistant phenotype was observed.

Association of Rps 1-k-3 transgenes with the disease resistant phenotype among $\mathrm{R}_{2}$ progenies descended from T-3-1 was not evident. Investigation of additional transformants gener-
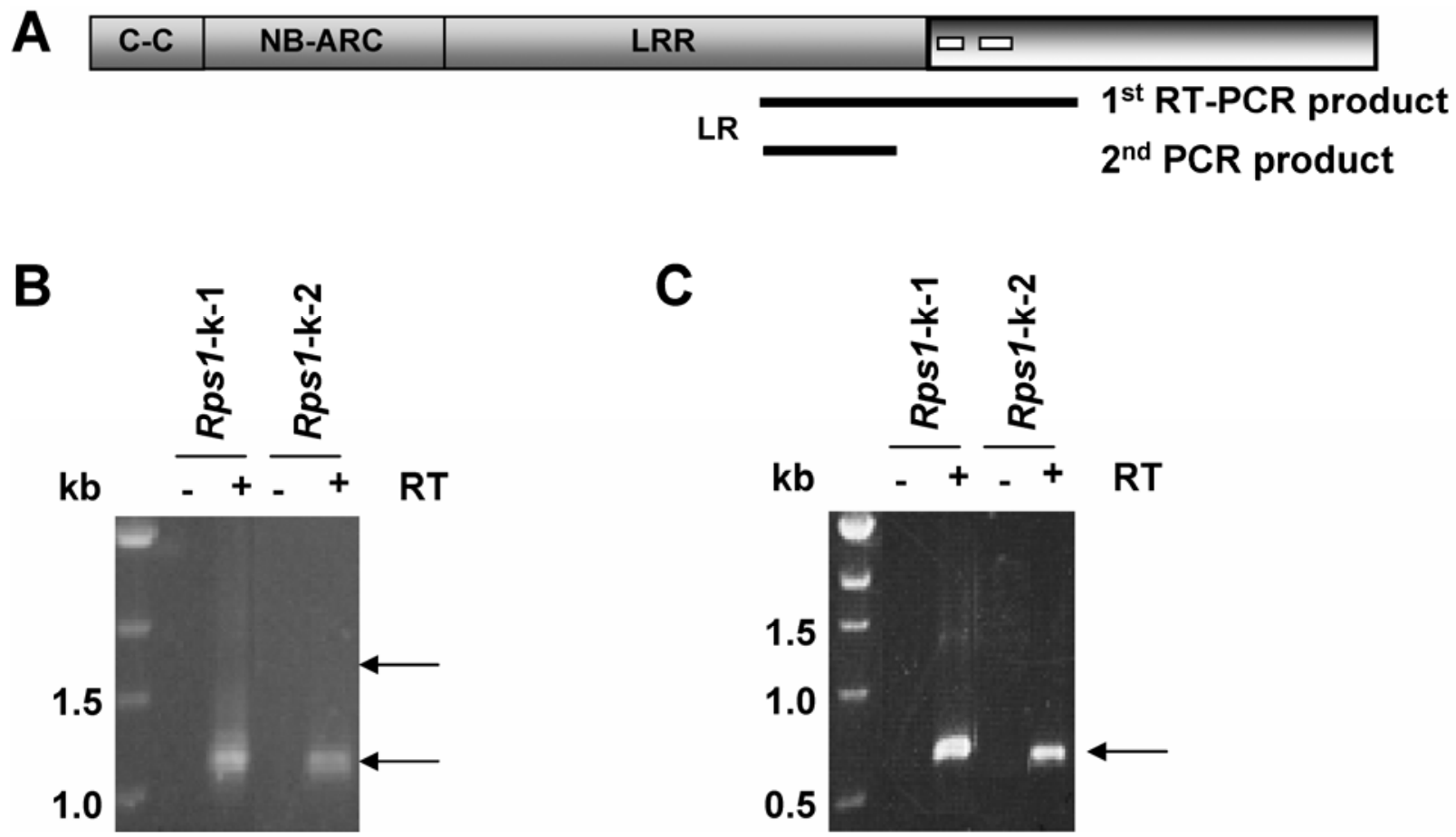

$1^{\text {st }}$ RT-PCR product

$2^{\text {nd }}$ PCR product

Fig. 3. Detection of candidate Rps1-k-specific transcripts. A, Schematic representation of the region considered for reverse transcription-polymerase chain reaction (RT-PCR) analyses.. Two white rectangles at the 3'-untranslated region are introns. The longer line indicates the region amplified through PCR following reverse transcription of total leaf RNAs. The shorter line shows the region considered for the second PCR. B, First RT-PCR products. RT $=$ reverse transcriptase, $+=$ with reverse transcriptase, and $-=$ without reverse transcriptase. The lower arrow shows the product obtained from the first RT-PCR. The upper arrow shows the PCR product from contaminating genomic DNA. C, Second PCR products. Sequence comparison revealed 100\% identity between the cDNA and gene sequences (data not shown). 
ated by transforming the cultivar Williams with Rps 1-k-1 also did not result in any clear-cut cosegregation of Rps $1-\mathrm{k}-1$ transgenes with the complemented resistant phenotype. Williams does not carry any known Rps genes. Transgenic Williams lines carrying Rps $1-\mathrm{k}-1$ transgenes showed resistance against race 1 , race 18, and isolate $997 \mathrm{~A}-2-3$. Transcript levels of the Rps $1-\mathrm{k}$ gene family are extremely low. Seven cDNA clones representing four gene members were isolated from screening 4.6 million PFU of an unamplified cDNA library (Bhattacharyya et al. 2005). However, none of these cDNAs showed complete sequence identity with any members of Class I or II genes (data not shown). Transcripts of these genes were detected only in a highly sensitive two-step RT-PCR experiment (Fig. 3). Recently, we have observed that transient overexpression of Rpsl-k-2 led to cell death (N. N. Narayanan and M. K. Bhattacharyya, unpublished data). Nearly undetectable transcript levels together with the cell death phenotype caused by overexpression of Rps l-k-2 suggested that, during transformation, expression of these genes at a higher level would be detrimental to the regeneration process. Although candidate genes with their own promoters were used in complementation analyses, the site of integration of these genes can greatly influence the levels of their expression (Butaye et al. 2004). Our failure to obtain a clear-cut cosegregation between transgene copies and Phytophthora resistance among transgenic lines could be attributed to low, unstable expression levels of more than one transgene copy among the transformants. Highly active transgenes were most likely silenced. This may also explain why we failed to observe any Phytophthora resistance among progenies of four Rps1-k-2 transformants (Table 1).

\section{Diversifying selection and frequency of mutation in Rps1-k genes.}

The solvent-exposed residues within the consensus repeat sequence xxLxLxx of LRR have been shown to be highly divergent and under substantial diversifying selection (Meyers et al. 1998; Parniske et al. 1997). Mondragon-Palomino and asso- ciates (2002) found strong positive selection in the LRR region by studying 163 NB-LRR genes of Arabidopsis thaliana. To determine the selection pressure exerted on the Rpsl-k gene family, ratios of nonsynonymous and synonymous substitution rates were calculated for different regions of the two classes of genes. The nonsynonymous substitution rate observed for the xxLxLxx repeat sequence of the LRR domain was statistically much higher than the nonsynonymous substitution rate $(P<$ 0.0001 at $5 \%$ level; Kumar et al. 2004; Table 3). This suggested that diversifying selection has been imposed on these solventexposed residues.

\section{Phylogenetic analysis}

of the Rps 1-k gene family and other CC-NB-LRR R genes.

Blastx and tblastn were carried out to study the relationship between Rps 1-k-2 and other plant disease-resistance genes and

Table 1. Segregation of resistant and susceptible $R_{1}$ progenies following inoculation with Phytophthora sojae race 4

\begin{tabular}{lrrcc}
\hline $\mathbf{R}_{\mathbf{0}}$ transformant $^{\mathbf{b}}$ & $\mathbf{R}$ & $\mathbf{S}$ & $\boldsymbol{X}_{(\mathbf{3 : 1})}$ & $\mathbf{P}\left(\boldsymbol{X}_{(\mathbf{3}: \mathbf{1})}\right)$ \\
\hline $\mathrm{T}-1-1^{\mathrm{c}}$ & 10 & 2 & 0.444 & 0.505 \\
$\mathrm{~T}-2-1^{\mathrm{c}}$ & 11 & 6 & 0.961 & 0.327 \\
$\mathrm{~T}-2-2$ & 2 & 1 & 39.185 & $<0.0001$ \\
$\mathrm{~T}-2-3$ & 2 & 15 & 36.255 & $<0.0001$ \\
$\mathrm{~T}-2-4$ & 0 & 16 & 48.000 & $<0.0001$ \\
$\mathrm{~T}-2-5$ & 5 & 10 & 13.899 & 0.0002 \\
$\mathrm{~T}-2-6^{\mathrm{d}}$ & - & - & - & - \\
$\mathrm{T}-3-1^{\mathrm{c}}$ & 13 & 5 & 0.074 & 0.785 \\
$\mathrm{~T}-3-2^{\mathrm{c}}$ & 11 & 7 & 1.852 & 0.174 \\
$\mathrm{~T}-3-3^{\mathrm{c}}$ & 13 & 5 & 0.074 & 0.785 \\
\hline
\end{tabular}

${ }^{a}$ Resistant and susceptible phenotypes were quantified by measuring lesion spread ( $\mathrm{mm} /$ day) in individual segregants.

${ }^{\mathrm{b}}$ Designations for transgenic plants: T- = transgenic plant; the first number indicates the Rps1-k gene number, e.g., T-1 for Rps $1-\mathrm{k}-1$, and the second number is the transformant number $\left(\mathrm{R}_{0}\right)$.

${ }^{c}$ Showed a 3:1 resistant/susceptible segregation ratio.

${ }^{d}$ Data unavailable for the $\mathrm{R}_{1}$ generation. A 3:1 resistant/susceptible segregation ratio was observed in the $\mathrm{R}_{2}$ generation.

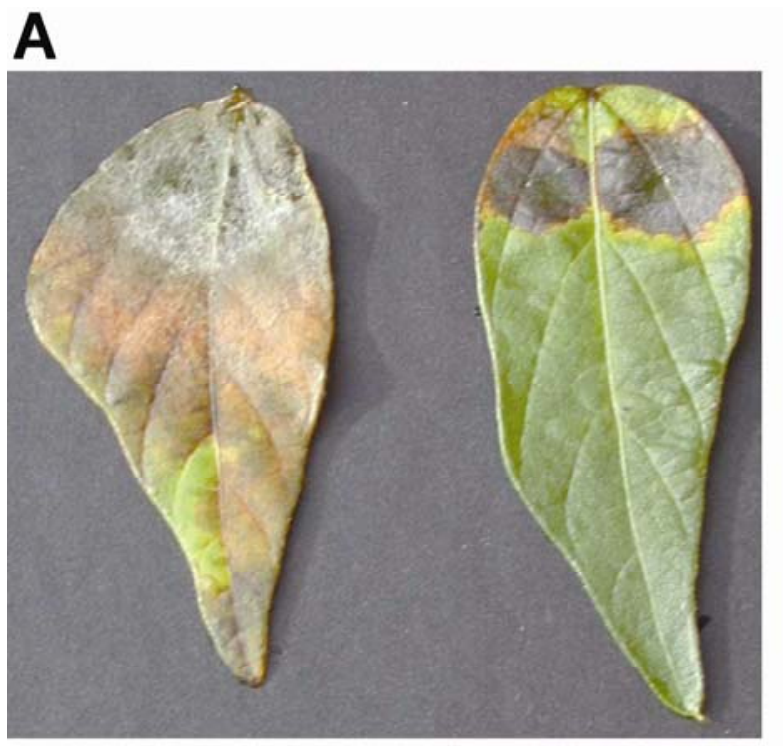

B

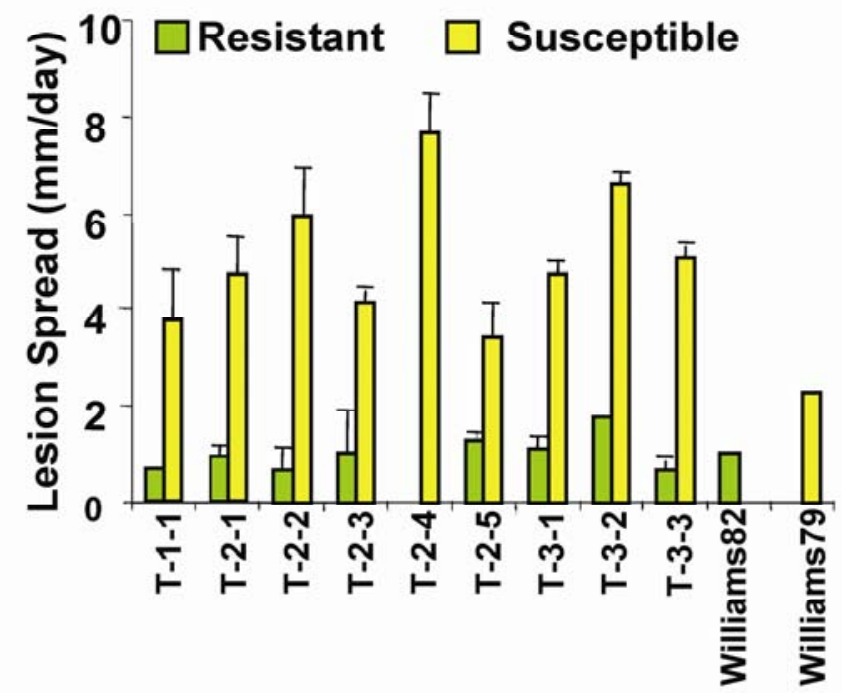

Fig. 4. Soybean transformants carrying candidate Rpsl-k genes confer Phytophthora resistance. A, A leaf (on the right) of a transformant $\left(\mathrm{R}_{0}\right)$ showed hypersensitive cell death and typical resistance response, whereas the leaf on the left from cultivar Williams 79, used as a recipient for the transformation, showed the typical susceptible response. B, Symptom development among $R_{1}$ progeny populations. Lesion sizes were recorded 2 and 3 days following inoculation with $P$. sojae race 4, and lesion spread (mm/day) was determined by subtracting the spread on day 3 from that on day 2 in millimeters. Standard errors of lesion spread among resistant (green bar) or susceptible (yellow bar) progenies are shown with lines at the top of each bar. Four disease lesions were measured for each plant. $\chi^{2}$ analyses of the data presented in B indicated a 3:1 segregation ratio for resistant to susceptible phenotypes for some of the $\mathrm{R}_{1}$ populations. Designations for transgenic plants: $\mathrm{T}-\mathrm{=}$ Transgenic plant, the first number indicates the Rps $1-\mathrm{k}$ gene number, e.g., T-1 for Rps 1 -k-1 and the second number is the transformant number $\left(\mathrm{R}_{0}\right)$. 
resistance-gene analogs (RGA). Complete amino acid sequences of the RGA or $R$ gene sequences (E-value $<\mathrm{e}^{-110}$ ) were either retrieved from GenBank or manually annotated by aligning deduced protein sequences using the ExPASy translate tool. Most of the cloned NB-LRR genes with a genetically validated resistance specificity were also collected from GenBank. A multiple sequence alignment of all retrieved protein sequences was performed, and a neighbor-joining tree was generated from the alignment. From this preliminary tree, CC-NB-LRRtype $\mathrm{R}$ proteins and representative RGA that are closely related to Rps1-k were selected to generate the final tree (Fig. 6). Rps1-k-2 showed high amino acid identities with the sequences from three legume species, including Glycine max, Medicago truncatula, and Lotus corniculatus. Deduced protein sequences of two L. corniculatus var. japonicus RGA showed the highest identity to the Rps1-k-2 protein sequence (59\%) and formed a very strongly supported group within the $R p s 1-\mathrm{k}$ gene family. This suggests that evolution of lotus RGA and Rpsl-k sequences may predate the separation of Lotus and Glycine genera. Although the possibility of convergent evolution of Rps $1-\mathrm{k}$ and lotus RGA sequences cannot be completely ruled out at this stage, evolution of these sequences from a single progenitor gene is the most likely alternative. If this is true, Rps $1-\mathrm{k}$ is a member of an ancient $R$ gene family. Among cloned $R$ genes, $R p s 1-\mathrm{k}$ is closely related to $R P G 1-b, I 2 C, X a 1, R p l-D$, and $R B$.

No close relationship among $R$ genes conferring resistance against a specific type of pathogen was observed. For example, $R p s 1$-k is highly diverged from $R l$, a potato $R$ gene that confers resistance against another Phytophthora pathogen, $P$. infestans. Potato Rx and Gpa 2 are paralogs, but they confer virus

Table 2. Responses of soybean cultivars or transformants to Phytophthora sojae race or isolate

\begin{tabular}{|c|c|c|c|c|c|}
\hline \multirow[b]{2}{*}{ Cultivar } & \multicolumn{5}{|c|}{$P$ sojae race/isolate responses ${ }^{a}$} \\
\hline & Race 1 & Race 4 & Isolate 997A-2-3 & Race 18 & Race 25 \\
\hline Williams (rps 1 ) & $\mathrm{S}$ & $\mathrm{S}$ & $\mathrm{S}$ & $\mathrm{S}$ & $\mathrm{S}$ \\
\hline Williams 79 (Rps1-c) & $\mathrm{R}$ & $\mathrm{S}$ & $\mathrm{S}$ & $\mathrm{S}$ & $\mathrm{S}$ \\
\hline Williams 82 (Rps $1-\mathrm{k})$ & $\mathrm{R}$ & $\mathrm{R}$ & $\mathrm{R}$ & $\mathrm{R}$ & $\mathrm{S}$ \\
\hline Transformant T-1-1(Rps1-k-1) & $\ldots{ }^{b}$ & $\mathrm{R}$ & $\mathrm{R}$ & $\mathrm{R}$ & $\mathrm{S}$ \\
\hline Transformant T-2-1(Rps $1-\mathrm{k}-2)^{\mathrm{c}}$ & $\ldots$ & $\mathrm{R}$ & $\mathrm{R}$ & $\mathrm{R}$ & $\mathrm{S}$ \\
\hline Transformant T-2-6 (Rpsl-k-2) & $\ldots$ & $\mathrm{R}$ & $\mathrm{R}$ & $\mathrm{R}$ & $\mathrm{S}$ \\
\hline Transformant T-3-1(Rps $1-\mathrm{k}-3)$ & $\ldots$ & $\mathrm{R}$ & $\mathrm{R}$ & $\mathrm{R}$ & $\mathrm{S}$ \\
\hline Transformant T-3-2 (Rps $1-\mathrm{k}-3)$ & $\ldots$ & $\mathrm{R}$ & $\mathrm{R}$ & $\mathrm{R}$ & $\mathrm{S}$ \\
\hline Transformant T-3-3 (Rps 1-k-3) & $\ldots$ & $\mathrm{R}$ & $\mathrm{R}$ & $\mathrm{R}$ & $\mathrm{S}$ \\
\hline Transformant 7aD-3 (Rps1-k-1) & $\mathrm{R}$ & $\ldots$ & $\mathrm{R}$ & $\mathrm{R}$ & $\mathrm{S}$ \\
\hline Transformant 7aD-6 (Rps1-k-1) & $\mathrm{R}$ & $\ldots$ & $\mathrm{R}$ & $\mathrm{R}$ & $\mathrm{S}$ \\
\hline Transformant 7aD-9 (Rps1-k-1) & $\mathrm{R}$ & $\ldots$ & $\mathrm{R}$ & $\mathrm{R}$ & $\mathrm{S}$ \\
\hline Transformant 30-85-1 (Rps1-k-2) & $\mathrm{R}$ & $\ldots$ & $\mathrm{R}$ & RS & $\mathrm{S}$ \\
\hline Transformant 30-85-5 (Rps 1-k-2) & $\mathrm{R}$ & $\ldots$ & $\mathrm{R}$ & RS & $\mathrm{S}$ \\
\hline Transformant 30-85-6 (Rps $1-\mathrm{k}-2)$ & $\mathrm{R}$ & $\ldots$ & $\mathrm{R}$ & RS & $\mathrm{S}$ \\
\hline
\end{tabular}

${ }^{\mathrm{a}} \mathrm{R}=$ resistant; $\mathrm{S}=$ susceptible; $\mathrm{RS}=$ resistant response with some spread of the lesions. ... indicates data not available.

${ }^{\mathrm{b}}$ Data is not available because the recipient cultivar, Williams 79, is resistant to race 1 .

${ }^{c}$ Responses of transformants are based on progeny testing.

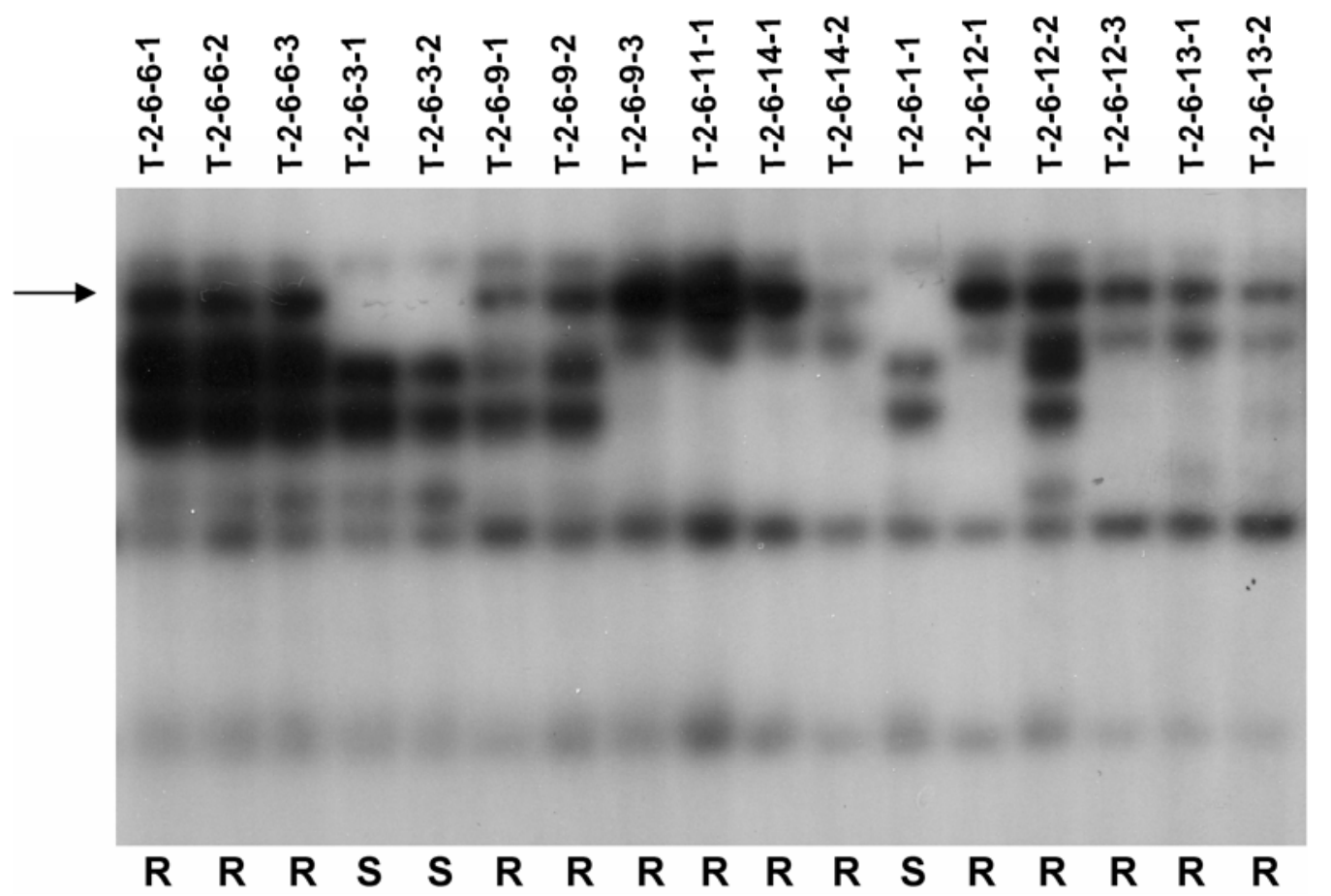

Fig. 5. Cosegregation of a transgene Rps $1-\mathrm{k}-2$ copy with the complemented resistant phenotype. Intact, etiolated hypocotyls of $\mathrm{R}_{3}$ progenies of the T-2-6 transformant containing the Rps1-k-2 transgene were inoculated with zoospore suspensions of the Phytophthora sojae isolate 997A-2-3. Randomly selected resistant and susceptible $\mathrm{R}_{3}$ progenies were analyzed for segregation of transgene copies by carrying out DNA blot analysis. The bar gene was used as the probe in this analysis. The arrow shows the transgene copy that cosegregated with the complemented resistant phenotype. 
and nematode resistance, respectively (van der Vossen et al. 2000). R proteins with high sequence similarity may not require the same signaling component. For example, although MLA1 and MLA6 proteins share $91.2 \%$ identity, MLA1 is Rarl-independent whereas MLA6 is Rarl-dependent (Halterman et al. 2001; Zhou et al. 2001). The phylogenetic tree indicated that most clades are family- or species-specific, which is consistent with the results of phylogentic analyses conducted for NB sequences of different plant families and species (Cannon et al. 2002; Meyers et al. 1999).

\section{DISCUSSION}

Two classes of CC-NB-LRR genes conferring Phytophthora resistance mapped to the Rps 1 -k locus.

In previous work, we isolated an approximately $145-\mathrm{kb}$ contiguous DNA fragment from the Rps $1-\mathrm{k}$ locus (Bhattacharyya et al. 2005). Sequencing of this gene-poor fragment allowed us to locate four CC-NB-LRR genes as candidates for Rpsl-k. Based on sequence similarities, we grouped these genes into two classes. Of these, Class II contains a single gene, Rps $1-\mathrm{k}-$ 2 , that showed stable expression of resistance in $R_{1}$ and $R_{2}$ generations of a transformants. Segregation analysis of the Rps 1-k-2 transgene confirmed that the gene is a functional Phytophthora resistance gene (Figs. 4 and 5; Tables 1 and 2).

The other three CC-NB-LRR Class I genes are identical in their nucleotide sequences. Cloning and characterization of these CC-NB-LRR genes were carried out through the subcloning of three overlapping BAC clones in a binary plasmid vector followed by sequencing. Two of the identical Class I genes, Rps 1-k-1 and Rps 1-k-4, were cloned from two nonoverlapping BACs that shared parts of the Rps $1-\mathrm{k}$ locus. The presence of a recombination breakpoint in the $3^{\prime}$ untranslated re-

Table 3. Rates of nonsynonymous (Ka) and synonymous (Ks) substitutions in the evolution of the Rps 1 -k gene family

\begin{tabular}{lc}
\hline Region/domain & $\mathbf{K a} / \mathbf{K s}^{\mathbf{a}}$ \\
\hline ORF & 0.625 \\
Coiled-coil domain & 0.29 \\
Nucleotide binding site domain & 0.33 \\
xxLxLxx $^{\mathrm{b}}$ & 2.33 \\
C-terminal region $^{\mathrm{c}}$ & 1 \\
\hline
\end{tabular}

${ }^{\mathrm{a}}$ The ratio of $\mathrm{Ka}$ and $\mathrm{Ks}$ substitution in variable sites was calculated by comparing the open reading frame (ORF) sequences of Class I (identical ORF of Rpsl-k-1, Rps 1 -k-3, and Rps 1 -k-4) and Class II (Rpsl-k-2) genes. The SNAP program was used in calculating the substitution values.

${ }^{\mathrm{b}}$ Conserved hydrophobic sites (L, V, F, and M) were not included in the calculation of the $\mathrm{Ka} / \mathrm{Ks}$ ratio of the xxLxLxx region.

${ }^{\mathrm{c}}$ Includes all of leucine-rich repeat and $\mathrm{F}$ domains except xxLxLxx motifs.

Fig. 6. Phylogenetic analysis of Rps 1-k and related sequences. A neighborjoining tree was constructed with the Molecular Evolutionary Genetics Analysis program (version 2.1) (Kumar et al. 2004). Full-length amino acid sequences of the $R$ genes and resistance gene analogs (RGAs) were aligned using ClustalW for phylogenetic analysis. The bootstrap values (percentages of 1,000 trees generated) for the nodes are indicated. The $N$ gene from tobacco was used as an outgroup sequence. Each characterized $\mathrm{R}$ protein is in bold font. The taxon name designation for functional $R$ proteins is the name of each $\mathrm{R}$ protein followed by the pathogen against which it confers resistance. $\mathrm{B}=$ bacterium, $\mathrm{F}=$ fungus, $\mathrm{N}=$ nematode, $\mathrm{O}=$ oomycete, $\mathrm{V}=$ virus, RPP13-Rld = RPP13 from Arabidopsis thaliana cv. Rld, RPP13-Nd = RPP13 from Arabidopsis thaliana cv. Neiderzens, and RPP13-C = RPP13 from Arabidopsis thaliana cv. Columbia. Each RGA was identified with a species prefix $(\mathrm{Gm}=$ Glycine $\max , \mathrm{Lc}=$ Lotus corniculatus, $\mathrm{Mt}=$ Medicago truncatula, $\mathrm{Os}=$ Oryza sativa , and $\mathrm{Pv}=$ Phaseolus vulgaris) followed by its GenBank accession number and the position from the bacterial artificial chromosome, if needed (as of October 11, 2004). gions distinguishes the third Class I gene, Rps1-k-3, from Rps 1-k-1 and Rps1-k-4. The functions of Rpsl-k-1 and Rps1$\mathrm{k}-3$ were studied in transgenic soybean plants. Multiple transgene copies were present in all transformants. However, among segregating $\mathrm{R}_{2}$ progenies developed from transforma-

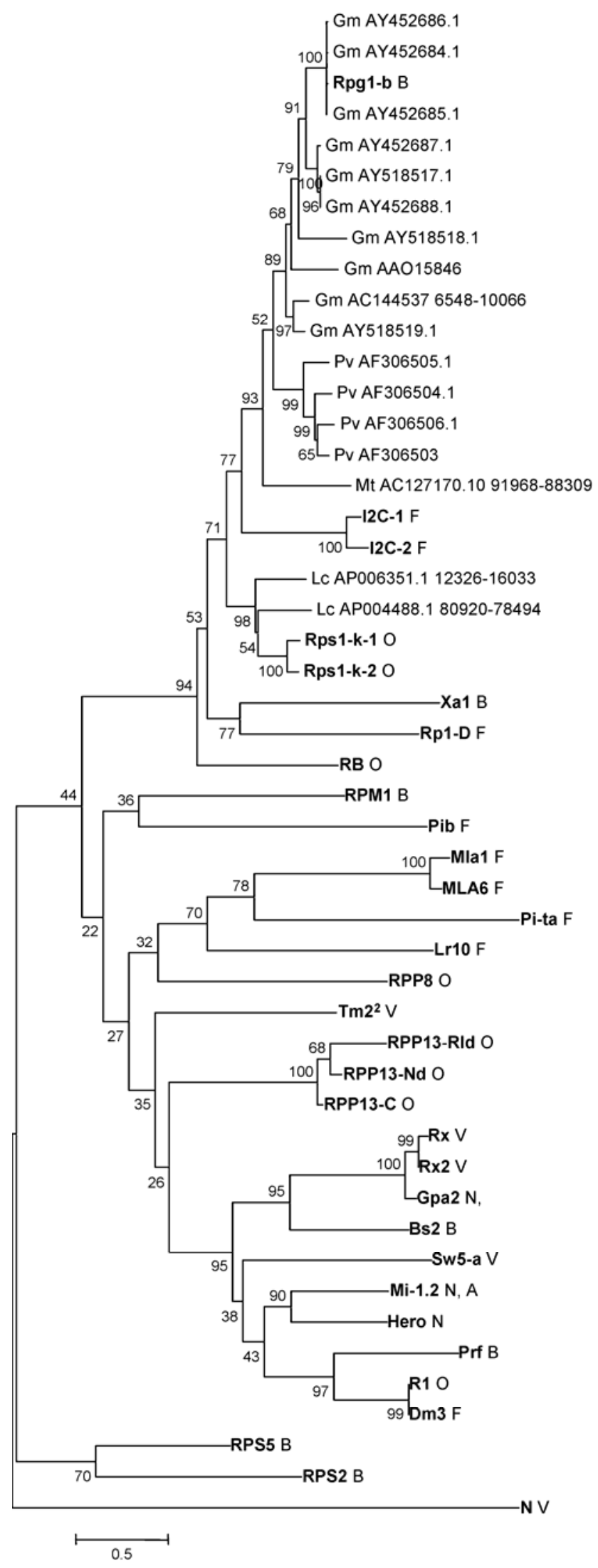

Vol. 18, No. 10, $2005 / 1041$ 
tion of either the cultivar Williams (rps1) or Williams 79 (Rps1-c) (Table 2), no association of Rps1-k-1 or Rps1-k-3 transgenes with the complemented Phytophthora-resistant phenotype was observed (data not presented). Transcript levels of the Rps 1-k gene family were very low and detectible only in highly sensitive RT-PCR experiments (Fig. 3). It is possible that an increased level of Rps1-k-1 or Rps1-k-3 protein is deleterious to plant cells, as was observed for Rps1-k-2 in transient overexpression experiments (N. N. Narayanan and M. K. Bhattacharyya, unpublished data). Therefore, most likely a selection pressure for poorly transcribed or nontranscribed transgene copies was exerted during transformation and regeneration to avoid any detrimental effects originating from high expression levels of $R p s 1-\mathrm{k}-1$ or $R p s 1-\mathrm{k}-3$ transgenes. A low level of expression from more than one transgene could account for the complemented resistant phenotype observed among transformants carrying Rpsl-k-3. From analyses of the ethylene mutant, etrl, it was concluded that there were most likely two Rps genes in the Rpsl-k locus, one of which requires the ethylene-signal pathway for expression of Phytophthora resistance (Hoffman et al. 1999). We therefore conclude that the Class I genes are most likely functional (Table 1).

\section{Evolution of the Rps1-k gene family.}

Progenitors of two classes of Rps 1 -k genes differ by 58 synonymous substitutions in the ORFs. Therefore, we calculated that the two progenitor genes probably started to diverge about 10 million years ago (Cronn et al. 2002). Although we have identified only four CC-NB-LRR genes at the Rps1-k locus, there are many additional members of the gene family in the Rps 1 region (Bhattacharyya et al. 2005). Therefore, it is possible that paralogous sequences of the Class II gene are located in the Rpsl-k-adjacent region.

Complete sequence identity among Class I Rpsl-k genes is unusual. To date, no two identical $R$ genes have been identified from the same haplotype. In flax, L3 and L10 carry identical ORFs while $L A$ differed from these two by a single nucleotide (Ellis et al. 1999). However, L3, L4, and L10 were characterized from three independent haplotypes. The only example of an $R$ locus containing highly similar genes is the tomato $C f 2$ locus, which carries two nearly identical resistance genes. These two genes differ only by three nucleotide residues (Dixon et al. 1996). Class I Rps 1-k genes are the only examples of identical $R$ genes isolated from a single locus.

Concerted evolution has been shown to have a major role in the evolution of tandemly arranged, identical repeat sequence families, such as snRNAs in humans and rDNA in yeast (Gangloff et al. 1996). It is unlikely that the high identity observed among members of the Rps 1 -k gene family resulted from concerted evolution. Homogenization, a requirement for concerted selection, acts against the diversification and generation of novel race-specificities. Parniske and his coworkers (1997) proposed that sequence homogenization could be prevented by the suppression of unequal recombination between two polymorphic, intergenic sequences. The relationship between physical and genetic distances at the Rps 1-k region is about $1: 1 \mathrm{Mb} / \mathrm{cM}$, and the region is not recombination-prone for sequence homogenization (Bhattacharyya et al. 2005). Gene conversion, a major sequence homogenization mechanism for concerted selection, was probably not the cause of $100 \%$ identity between Class I Rps 1-k genes of about 9 to $10 \mathrm{~kb}$ of DNA including 5' and 3' end sequences. Gene conversion tracts are mostly limited to ORFs and are relatively small (Drouin 2002).

Complete identity among Class I Rps 1 -k genes suggests that the genes were duplicated very recently through unequal crossing over, which is considered to be an important mechanism for the evolution of disease-resistance genes. In maize, unequal crossing over is the main mechanism of meiotic instability at the $R p 1$ region (Sudupak et al. 1993). In the Arabidopsis ecotype Columbia, the nonfunctional, chimeric rpp8 gene most likely evolved from unequal crossing over between the functional oomycete resistance gene RPP 8 and its homolog, $R P H 8 A$ (McDowell et al. 1998). It has been proposed that the $H R T$ gene encoding viral resistance evolved by unequal crossing over between progenitor genes related to RPP8 and RPH8A (Cooley et al. 2000). Unequal crossing over has also been considered to play an important role in the generation of alleles at the Rsv1 locus in soybean (Hayes et al. 2004). Unequal crossing over most likely occurs from the pairing of diverse haplotypes following cross-fertilization. This leads to tandem accumulation of similar but usually not identical paralogous genes, because diverse haplotypes are expected to accumulate mutations in paralogous genes.

Two unequal crossing over events were detected at the Rps 1-k region, one at the physically linked TC1 and 18R loci (Bhattacharyya et al. 2005) and the other one at the $3^{\prime}$ end of Rps1-k-3 (Fig. 1). Soybean is predominantly a self-pollinated species, and it is very unlikely that three identical genes evolved from unequal crossing over events between diverse haplotypes of two genotypes. Considering the highly self-pollinated nature of soybean, the probability of open pollination between two diverse genotypes for unequal crossing over events in the recent past is very small. It is very unlikely that unequal crossing over events between Rps I-k and rps I-k haplotypes can lead to the evolution of identical, functional Class I Rps l-k genes during introgression of the gene into Williams 82 from Kingwa, because the recurrent parent Williams does not contain any known functional Rpsl genes for contributing toward the gene duplication phenomenon. Considering the predominantly self-pollinated nature of soybean and $100 \%$ identity among Class I genes in a small genomic region, we propose that, during meiosis, slippage in pairing or mispairing between tandem paralogous rather than orthologous sequences of two sister chromatids of a homozygous plant resulted in the evolution of three identical Class I Rpsl-k genes. Tightly linked, paralogous genes can mispair during meiosis, resulting in gene duplication, deletions, and evolution of chimeric genes. Jelesko and associates (2004) recently provided experimental evidence for recombination between misaligned paralogous sequences of sister chromatids during meiosis in the selfpollinated species, Arabidopsis. The presence of such a local gene duplication mechanism from misaligned sister chromatids in a self-pollinated plant species such as soybean can result in substrates for the generation of new genetic variations for some traits that require rapid evolution.

\section{MATERIALS AND METHODS}

\section{Subcloning and sequencing of BAC clones.}

Three overlapping BAC clones, BAC18, BAC43, and BAC99, carrying the Rpsl-k locus, were sequenced by applying a shotgun cloning approach. To minimize Escherichia coli DNA contamination, BAC DNA samples were prepared using the Qiagen large construct kit (Qiagen, Valencia, CA, U.S.A.). Two shotgun libraries for each BAC clone were constructed. One of these libraries was constructed using the Topo shotgun subcloning kit (Invitrogen, Carlsbad, CA, U.S.A.). Individual BAC DNA samples were nebulized under pressure at 5 psi for $10 \mathrm{~s}$. Fragments (5 to $10 \mathrm{~kb}$ ) were blunt-ended, dephosphorylated, and ligated to the vector pCR4BluntTOPO. The second library was constructed by using partially digested Sau3AI DNA fragments. Following partial restriction, the partially digested DNA fragments were fractionated on an agarose gel, and frag- 
ments of approximately $20 \mathrm{~kb}$ were purified and ligated into the dephosphorylated BamHI site of the binary vector, pTF101.1 (Paz et al. 2004). Ligated DNA samples were electroporated into $E$. coli $\mathrm{DH} 10 \mathrm{~B} \alpha$ using the Cell porator $E$ coli pulser (Invitrogen, Carlsbad, CA, U.S.A.). The resultant recombinant plasmids, generated from cloning into pCR4BluntTOPO and pTF101.1, were named TOPO and pTF101.1 clones, respectively. Colonies from each library were picked randomly and stored in 96-well microtiter plates. Plasmid DNA was prepared using the Montage plasmid miniprep $_{96}$ kit (Millipore, Bedford, MA, U.S.A.). Both ends of each clone were sequenced in an ABI PRISM 3700 analyzer at the DNA Sequencing Facility, Iowa State University.

The sequence data were assembled utilizing Phred/Phrap software on a PC with a Linux operating system. The resulting contigs of each BAC were manually ordered into a scaffold by using the read-pairs. Primer walking was applied to fill out most of the remaining gaps. The assembled sequences were searched against GenBank using the BlastX algorithm. A series of primers for every 200 to $300 \mathrm{bp}$ of each DNA strand were designed based on the consensus sequence of the candidate Rps l-k genes. The primers were then used in sequencing the selected pTF101.1 clones as described in the next section.

\section{Sequence analyses of CC-NB-LRR clones.}

Sequences of each insert end in pTF101.1 clones were investigated for possible homology to candidate Rps l-k gene sequences. pTF101.1 clones showing no homologies to the candidate Rps 1 -k gene sequences were selected for Southern blotting experiments and were hybridized to NBS and LRR domain-specific probes developed from one of the Rps $1-\mathrm{k}$ genes. The pTF101.1 clones hybridizing to both probes were classified into seven putative groups by conducting DNA fingerprint analysis. A total of 13 clones selected from these seven groups were sequenced, using primers designed based on the consensus CC-NB-LRR sequences generated from the comparison of BAC contig sequences described in the previous section. Each nucleotide was sequenced at least three times. The sequence reads of each clone were assembled using the Vector NTI Suite 6 program (v.6 for PC, InforMax Inc.; Invitrogen). Four CC-NB-LLR genes were identified from sequencing of pTF101.1 clones. The genes were predicted using the Genscan program and BlastX algorithm search.

\section{Generation of transgenic soybean plants.}

Three binary plasmids in the pTF101.1vector, p43-JP1 (Rps1-k-1), p99-6A (Rpsl-k-2), and p43-10 (Rps1-k-3), were electroporated into Agrobacterium tumefaciens EHA101. The agrobacteria containing the binary plasmids were used to transform cotyledonary explants of the cultivars Williams (rps 1) or Williams 79 (Rps1-c) at the plant transformation facility at Iowa State University (Table 2; Paz et al. 2004).

A total of 16 seeds of each $\mathrm{R}_{0}$ transformant were germinated, and 3-day-old seedlings were transferred to soil in small paper pots. After growth for 5 days in the greenhouse, followed by hardening in sunlight for 2 days, $\mathrm{R}_{1}$ plants containing transgenes Rpsl-k-1, Rpsl-k-2, and Rpsl-k-3 were transplanted at the Bruner farm, Iowa State University, in 2002. $\mathrm{R}_{2}$ seeds of individual plants were harvested, stored, and threshed after about four months. In $2003, \mathrm{R}_{3}$ seeds were generated by growing $R_{2}$ plants at the Bruner farm.

\section{Growing of soybean and Phytophthora sojae.}

Transgenic and nontransgenic soybean seedlings were grown under dark or light conditions in growth chambers at the Agronomy Department, Iowa State University (Bhattacharyya and Ward 1986; Ward et al. 1979). P. sojae race 1, race 4, race 18, race 25 , and isolate $997 \mathrm{~A}-2-3$ were grown in the dark at $22^{\circ} \mathrm{C}$, and zoospores were prepared from 6-day-old cultures (Table 2; Ward et al. 1979).

\section{Evaluation of transgenic soybean plants \\ for resistance against Phytophthora sojae.}

Trifoliate leaves of $\mathrm{R}_{0}$ transformants were inoculated with $P$. sojae race 4 as follows. Trifoliate leaves were detached and placed in petri dishes (90-mm diameter) containing Whatman filter papers moistened with $10 \mathrm{ml}$ of water. Petioles were kept under a film of water, and each half of the leaf blade was inoculated with a single droplet of zoospore suspension (Bhattacharyya and Ward 1986). Subsequently, unifoliate leaves of $\mathrm{R}_{1}$ progenies of independent transformants containing either Rps1-k-1, Rpsl-k-2, or Rpsl-k-3 transgene were tested for Phytophthora resistance. Symptoms were evaluated 48 and 72 $\mathrm{h}$ following inoculation. The average lesion spread in millimeters per day was then determined for all lesions of an individual class of disease phenotype. A resistant phenotype was characterized by dark brown lesions that spread very slowly, whereas a susceptible phenotype was characterized by a very light brown lesion that spread rapidly.

Wounded hypocotyls instead of leaves of $R_{2}$ or $R_{3}$ populations were inoculated, because the wounded-hypocotyl inoculation method requires less space than the leaf inoculation procedure and a large number of plants can be infected in a small space under uniform environmental conditions (Haas and Buzzell 1976). For the wounded-hypocotyl inoculation method, soybean seedlings were grown in coarse vermiculite for 7 to 8 days, until the cotyledons expanded completely. $P$. sojae race 997A-2-3 was grown in V8 agar diluted by onefourth, until the mycelia covered the entire petri plate $(90-\mathrm{mm}$ diameter). The culture was cut into strips and was placed in a 10-ml BD syringe (Becton, Dickinson and Co., Franklin, NJ, U.S.A.). The culture was then macerated by passing through a precision glide $18 \mathrm{G} \times 1 \frac{1}{2} 2$ needle (Becton, Dickinson and Co.). With the help of the needle tip, a slit of about $1 \mathrm{~cm}$ long was made in the hypocotyl just below the cotyledonary nodes. About 0.2 to $0.4 \mathrm{ml}$ of the macerated culture slurry was inserted into the slit with the help of a syringe. The plants were incubated under a 16-h light and 8-h dark period for disease development. Disease phenotypes were recorded 48, 60, 72, and 84 $\mathrm{h}$ following inoculation. Dark-grown seedlings were inoculated with $P$. sojae zoospore suspensions, as described by Ward and associates (1979), and were evaluated $24 \mathrm{~h}$ following inoculation.

\section{DNA gel blot analysis.}

Soybean genomic DNA was prepared from individual transgenic plants according to White and Kaper (1989). DNA from each genotype $(10 \mu \mathrm{g})$ was digested overnight with HindIII and was fractionated on a $0.8 \%$ agarose gel. The selectable marker gene bar was used as a probe (Paz et al. 2004). The gene was PCR-amplified from the plasmid pTF101.1 by using two primers (upstream forward primer: 5'-CAGCTGCCAGAA ACCCACGT-3'; and downstream reverse primer: 5'-CTGCAC CATCGTCAACCACT-3'). Prehybridization and hybridization of DNA filters were carried out according to Kasuga and associates (1997).

\section{RT-PCR.}

Total RNA was isolated from soybean leaf tissues by using the RNeasy plant mini kit (Qiagen). For RT-PCR experiments, cDNAs were synthesized from total RNAs using M-MLV reverse transcriptase (Promega, Madison, WI, U.S.A.). Primers for the first round of PCR experiments were: ClassI:F, 5'-ACC TGGATCCCTGAAGAGTCTGTATATCTC-3'; ClassII:F, 5'-C 
CCAAGCTTGCAGAGTCATTTAAGAGTCTGTGTTATTTG TTA-3'; Common:R, 5'-CCCAAGCTTAATTCACTTGGTAC ACCTTTTCATCCTTCAC-3'. Primers for the second round of PCR experiments were: ClassI:F, 5'-ACCTGGATCCCTGAA GAGTCTGTATATCTC-3'; ClassI:R 5'-AATTGGATCCGAG AGTCAGGAAGCCTTTCTCCCA-3'; ClassII:F, 5'-CCCAAG CTTGCAGAGTCATTTAAGAGTCTGTGTTATTTGTTA-3'; ClassII:R 5'-GCGGGATCCTTTTTCCAGCAAAGGACATTC CACC-3'.

\section{ACKNOWLEDGMENTS}

We are grateful to J. M. Peterson, P. A. Peterson, D. Sandhu, K. G. Schallock, P. S. Schnable, J. Seibel, and R. C. Shoemaker for reviewing this manuscript. We are also grateful to K. Wang and her group for developing the transgenic soybean plants at the Plant Transformation Facility, ISU, and R. Palmer and his group for their kind assistance in growing and threshing the transgenic soybean plants. $P$. sojae races were kindly provided by $\mathrm{M}$. Gijzen and the $P$. sojae isolate by T. Anderson. This research has been supported by United States Department of Agriculture-National Research Initiative grant number 2001-35301-10577, Iowa Soybean Promotion Board, and an ISU Agronomy Department Endowment Fund.

\section{LITERATURE CITED}

Ashfield, T., Ong, L. E., Nobuta, K., Schneider, C. M., and Innes, R. W. 2004. Convergent evolution of disease resistance gene specificity in two flowering plant families. Plant Cell 16:309-318.

Ballvora, A., Ercolano, M. R., Weiss, J., Meksem, K., Bormann, C. A., Oberhagemann, P., Salamini, F., and Gebhardt, C. 2002. The RI gene for potato resistance to late blight (Phytophthora infestans) belongs to the leucine zipper/NBS/LRR class of plant resistance genes. Plant J. 30:361-371.

Bent, A. F., Kunkel, B. N., Dahlbeck, D., Brown, K. L., Schmidt, R., Giraudat, J., Leung, J., and Staskawicz, B. J. 1994. RPS2 of Arabidopsis thaliana: A leucine-rich repeat class of plant disease resistance genes. Science 265:1856-1860.

Bhattacharyya, M. K., and Ward, E. W. B. 1986. Expression of gene-specific and age-related resistance and the accumulation of glyceollin in soybean leaves infected with Phytophthora megasperma f. sp. glycinea. Physiol. Mol. Plant Pathol. 29:105-113.

Bhattacharyya, M. K., Narayanan, N. N., Gao, H., Santra, D. K., Salimath, S. S., Kasuga, T., Liu, Y., Espinosa, B., Ellison, L., Marek, L., Shoemaker, R., Gijzen, M., and Buzzell, R. I. 2005. Identification of a large cluster of coiled coil-nucleotide binding site-leucine rich repeattype genes from the Rps1 region containing Phytophthora resistance genes in soybean. Theor. Appl. Genet. 111:75-86.

Butaye, K. M. J., Goderis, I. J. W. M., Wouters, P. F. J., Pues, J. M.-T. G., Delauré, S. L., Broekaert, W. F., Depicker, A., Cammue, B. P. A., and De Bolle, M. F. C. 2004. Stable high-level transgene expression in Arabidopsis thaliana using gene silencing mutants and matrix attachment regions. Plant J. 39:440-449.

Cannon, S. B., Zhu, H., Baumgarten, A. M., Spangler, R., May, G., Cook, D. R., and Young, N. D. 2002. Diversity, distribution, and ancient taxonomic relationships within the TIR and non-TIR NBS-LRR resistance gene subfamilies. J. Mol. Evol. 54:548-562.

Cooley, M. B., Pathirana, S., Wu, H. J., Kachroo, P., and Klessig, D. F. 2000. Members of the Arabidopsis HRT/RPP8 family of resistance genes confer resistance to both viral and oomycete pathogens. Plant Cell 12:663-676.

Cronn, R. C., Small, R. L., Haselkorn, T., and Wendel, J. F. 2002. Rapid diversification of the cotton genus (Gossypium: Malvaceae) revealed by analysis of sixteen nuclear and chloroplast genes. Am. J. Bot. 89:707725 .

Deslandes, L., Olivier, J., Theulieres, F., Hirsch, J., Feng, D. X., BittnerEddy, P., Beynon, J., and Marco, Y. 2002. Resistance to Ralstonia solanacearum in Arabidopsis thaliana is conferred by the recessive $R R S 1-R$ gene, a member of a novel family of resistance genes. Proc. Natl. Acad. Sci. U.S.A. 99:2404-2409.

Dixon, M. S., Jones, D. A., Keddie, J. S., Thomas, C. M., Harrison, K., and Jones, J. D. 1996. The tomato Cf-2 disease resistance locus comprises two functional genes encoding leucine-rich repeat proteins. Cell $84: 451-459$

Drouin, G. 2002. Characterization of the gene conversions between the multigene family members of the yeast genome. J. Mol. Evol. 55:14-23. Ellis, J. G., Lawrence, G. J., Luck, J. E., and Dodds, P. N. 1999. Identifica- tion of regions in alleles of the flax rust resistance gene $L$ that determine differences in gene-for-gene specificity. Plant Cell 11:495-506.

Flor, H. H. 1955. Host-parasite interaction in flax rust-Its genetics and other implications. Phytopathology 45:680-685.

Gangloff, S., Zou, H., and Rothstein, R. 1996. Gene conversion plays the major role in controlling the stability of large tandem repeats in yeast. EMBO (Eur. Mol. Biol. Organ.) J. 15:1715-1725.

Graham, M. A., Marek, L. F., and Shoemaker, R. C. 2002. Organization, expression and evolution of a disease resistance gene cluster in soybean. Genetics 162:1961-1977.

Haas, J. H., and Buzzell, R. I. 1976. New races 5 and 6 of Phytophthora megasperma var. sojae and differential reactions of soybean cultivars for races 1 to 6 . Phytopathology 66:1361-1362.

Halterman, D., Zhou, F., Wei, F., Wise, R. P., and Schulze-Lefert, P. 2001. The MLA6 coiled-coil, NBS-LRR protein confers AvrMla6-dependent resistance specificity to Blumeria graminis f. sp. hordei in barley and wheat. Plant J. 25:335-348.

Hammond-Kosack, K. E., and Jones, J. D. 1996. Resistance gene-dependent plant defense responses. Plant Cell 8:1773-1791.

Hayes, A. J., Jeong, S. C., Gore, M. A., Yu, Y. G., Buss, G. R., Tolin, S. A., and Maroof, M. A. 2004. Recombination within a nucleotide-bindingsite/leucine-rich-repeat gene cluster produces new variants conditioning resistance to soybean mosaic virus in soybeans. Genetics 166:493-503.

Hoffman, T., Schmidt, J. S., Zheng, X., and Bent, A. F. 1999. Isolation of ethylene-insensitive soybean mutants that are altered in pathogen susceptibility and gene-for-gene disease resistance. Plant Physiol. 119:935950.

Huang, L., Brooks, S. A., Li, W., Fellers, J. P., Trick, H. N., and Gill, B. S. 2003. Map-based cloning of leaf rust resistance gene Lr21 from the large and polyploid genome of bread wheat. Genetics 164:655-664.

Hulbert, S. H., Webb, C. A., Smith, S. M., and Sun, Q. 2001. Resistance gene complexes: Evolution and utilization. Annu. Rev. Phytopathol. 39:285-312.

Jelesko, J. G., Carter, K., Thompson, W., Kinoshita, Y., and Gruissem, W. 2004. Meiotic recombination between paralogous $R B C S B$ genes on sister chromatids of Arabidopsis thaliana. Genetics 166:947-957.

Kasuga, T., Salimath, S., Shi, J., Gijzen, M., Buzzell, R. I., and Bhattacharyya, M. K. 1997. High resolution genetic and physical mapping of molecular markers linked to the Phytophthora resistance gene Rps 1-k in soybean. Mol. Plant Microbe Interact. 10:1035-1044.

Kumar, S., Tamura, K., and Nei, M. 2004. MEGA3: Integrated software for molecular evolutionary genetics analysis and sequence alignment. Briefings Bioinformatics 5:150-163.

Lahaye, T. 2004. Illuminating the molecular basis of gene-for-gene resistance; Arabidopsis thaliana RRS1-R and its interaction with Ralstonia solanacearum popP2. Trends Plant Sci. 9:1-4.

Lupas, A. 1997. Predicting coiled-coil regions in proteins. Curr. Opin. Struct. Biol. 7:388-393.

Marathe, R., and Dinesh-Kumar, S. P. 2003. Plant defense: One post, multiple guards?! Mol Cell. 11:284-286.

Martin, G. B., Bogdanove, A. J., and Sessa, G. 2003. Understanding the functions of plant disease resistance proteins. Annu. Rev. Plant Biol. 54:23-61

McDowell, J. M., Dhandaydham, M., Long, T. A., Aarts, M. G., Goff, S., Holub, E. B., and Dangl, J. L. 1998. Intragenic recombination and diversifying selection contribute to the evolution of downy mildew resistance at the RPP8 locus of Arabidopsis. Plant Cell 10:1861-1874.

Meyers, B. C., Shen, K. A., Rohani, P., Gaut, B. S., and Michelmore, R. W. 1998. Receptor-like genes in the major resistance locus of lettuce are subject to divergent selection. Plant Cell 10:1833-1846.

Meyers, B. C., Dickerman, A. W., Michelmore, R. W., Sivaramakrishnan, S., Sobral, B. W., and Young, N. D. 1999. Plant disease resistance genes encode members of an ancient and diverse protein family within the nucleotide-binding superfamily. Plant J. 20:317-332.

Mondragon-Palomino, M., Meyers, B. C., Michelmore, R. W., and Gaut, B. S. 2002. Patterns of positive selection in the complete NBS-LRR gene family of Arabidopsis thaliana. Genome Res. 12:1305-1315.

Ori, N., Eshed, Y., Paran, I., Presting, G., Aviv, D., Tanksley, S., Zamir, D., and Fluhr, R. 1997. The $I 2 C$ family from the wilt disease resistance locus $I 2$ belongs to the nucleotide binding, leucine-rich repeat superfamily of plant resistance genes. Plant Cell 9:521-532.

Pan, Q., Wendel, J., and Fluhr, R. 2000. Divergent evolution of plant NBSLRR resistance gene homologues in dicot and cereal genomes. J. Mol. Evol. 50:203-213.

Parniske, M., Hammond-Kosack, K. E., Golstein, C., Thomas, C. M., Jones, D. A., Harrison, K., Wulff, B. B., and Jones, J. D. 1997. Novel disease resistance specificities result from sequence exchange between tandemly repeated genes at the $C f-4 / 9$ locus of tomato. Cell 91:821-832.

Paz, M. M., Shou, H., Guo, Z., Zhang Z., Banerjee, A. J., and Wang, K. 2004. Assessment of conditions affecting Agrobacterium-mediated soy- 
bean transformation using the cotyledonary node explant. Euphytica 136:167-179.

Sandhu, D., Gao, H., Cianzio, S., and Bhattacharyya, M. K. 2004. Deletion of a disease resistance nucleotide-binding-site leucine-rich-repeatlike sequence is associated with the loss of the Phytophthora resistance gene Rps4 in soybean. Genetics 168:2157-2167.

Schmitthenner, A. F., Hobe, M., and Bhat, R. G. 1994. Phytophthora sojae races in Ohio over a 10-year interval. Plant Dis. 78:269-276.

Shan, W., Cao, M., Leung, D., and Tyler, B. M. 2004. The Avrlb locus of Phytophthora sojae encodes an elicitor and a regulator required for avirulence on soybean plants carrying resistance gene Rps $1 b$. Mol Plant-Microbe Interact. 17:394-403.

Shao, F., Golstein, C., Ade, J., Stoutemyer, M., Dixon, J. E., and Innes, R. W. 2003. Cleavage of Arabidopsis PBS1 by a bacterial type III effector. Science 301:1230-1233.

Sudupak, M. A., Bennetzen, J. L., and Hulbert, S. H. 1993. Unequal exchange and meiotic instability of disease-resistance genes in the Rpl region of maize. Genetics 133:119-125.

Tyler, B. M. 2002. Molecular basis of recognition between phytophthora pathogens and their hosts. Annu. Rev. Phytopathol. 40:137-167.

van der Biezen, E. A., and Jones, J. D. 1998. The NB-ARC domain: A novel signaling motif shared by plant resistance gene products and regulators of cell death in animals. Curr. Biol. 8:R226-227.

van der Vossen, E. A., van der Voort, J. N., Kanyuka, K., Bendahmane, A., Sandbrink, H., Baulcombe, D. C., Bakker, J., Stiekema, W. J., and Klein-Lankhorst, R. M. 2000. Homologues of a single resistance-gene cluster in potato confer resistance to distinct pathogens: A virus and a nematode. Plant J. 23:567-576.

Vos, P., Simons, G., Jesse, T., Wijbrandi, J., Heinen, L., Hogers, R., Frijters, A., Groenendijk, J., Diergaarde, P., Reijans, M., FierensOnstenk, J., de Both, M., Peleman, J., Liharska, T., Hontelez, J., and Zabeau, M. 1998. The tomato Mi-1 gene confers resistance to both rootknot nematodes and potato aphids. Nat. Biotechnol. 16:1365-1369.
Ward, E. W. B., Lazarovits, G., Unwin, C. H., and Bizzell, R. I. 1979. Hypocotyl reactions and glyceollin in soybeans inoculated with zoospores of Phytophthora megasperma var. sojae. Phytopathology 69:951-955.

White, J. L., and Kaper, J. M. 1989. A simple method for detection of viral satellite RNAs in small plant tissue samples. J. Virol. Methods 23:83-94.

Whitham, S., Dinesh-Kumar, S. P., Choi, D., Hehl, R., Corr, C., and Baker, B. 1994. The product of the tobacco mosaic virus resistance gene $N$ : Similarity to toll and the interleukin-1 receptor. Cell 78:1101-1115.

Wrather, J. A., Anderson, T. R., Arsyad, D. M., Tan, Y., Ploper, L. D., Porta-Puglia, A., Ram, H. H., and Yorinori, J. T. 2001. Soybean disease loss estimates for the top ten soybean-producing counries in 1998. Can. J. Plant Pathol. 23:115-121.

Zhou, F., Kurth, J., Wei, F., Elliott, C., Vale, G., Yahiaoui, N., Keller, B., Somerville, S., Wise, R., and Schulze-Lefert, P. 2001. Cell-autonomous expression of barley Mlal confers race-specific resistance to the Powdery mildew fungus via a Rarl-independent signaling pathway. Plant Cell 13:337-350.

\section{AUTHOR-RECOMMENDED INTERNET RESOURCES}

The Expert Protein Analysis System (ExPASy) proteomics server's translate tool: us.expasy.org/tools/dna.html

Los Alamos National Laboratory's SNAP (Synonymous/Non-synonymous Analysis Program): hiv-web.lanl.gov/content/hivdb/SNAP/WEBSNAP/SNAP.html

National Center for Biotechnology Information Blast webpage: www.ncbi.nlm.nih.gov/BLAST/

The New GENSCAN Web Server at MIT webpage: genes.mit.edu/GENSCAN.html

The Wellcome Trust Sanger Institute's Pfam database (protein family alignments and HMMs): www.sanger.ac.uk/Software/Pfam/search.shtml 